\title{
Lifestyle and its Impact on the General and Bucal Health Situation of the Elderly Adult of the House of the Elderly Adult of Squirting. Lima 2014
}

\author{
Rosa Elizabeth Ysla Cheé ${ }^{*}$, María del Carmen Pareja Vásquez ${ }^{2}$ and Jaime Carlos Porras Cerrón ${ }^{3}$ \\ ${ }^{1}$ Specialist Professor of Periodontics II, Doctor in Public Health, Doctor of Dentistry, Peru \\ ${ }^{2}$ Coordinator of the Periodontics Subject II, Periodontist specialist doctor, Doctor of Education, Peru \\ ${ }^{3}$ Coordinator of the Master of Applied Statistics of the Agrarian University La Molina, Peru
}

*Corresponding author: Rosa Elizabeth Ysla Cheé, Specialist Professor of Periodontics II, Doctor in Public Health, Doctor of

Dentistry, Peru

\section{ARTICLE INFO}

Received: 豐 November 11, 2019

Published: 慧 November 20, 2019

Citation: Rosa Elizabeth Ysla Cheé, María del Carmen Pareja Vásquez, Jaime Carlos Porras Cerrón. Lifestyle and its Impact on the General and Bucal Health Situation of the Elderly Adult of the House of the Elderly Adult of Squirting. Lima 2014. Biomed J Sci \& Tech Res 23(1)-2019. BJSTR. MS.ID.003849.

Keywords: Elderly; Life's style; Impact; CPITN; Senior Adult

\section{ABSTRACT}

Objective: The purpose of this study was to asses life's style of Elderly and related with general and oral health.

Methodology: 44 subjects were interviewed with a questionnaire having as variables assesed as diet, physic activity, intellectual function, etc. Clinical tests were registered in a clinical history. We use oral indexes as: ISHO, CPTTN, CPOd, Löe Silness to measure oral hygiene, periodontal status, dental caries, gingivitis.

We used validized items to get a life's style index which had the several punctuations: 57-60 very healthy, 51-56 healthy an -50 or least less healthy. We had got 37 least healthy and 7 healthy

Results: DMF index was 19.98. The highest prevalence of periodontal illness was calculus and blooding. Among systemic sickness hypertension, diabetes and stress were more frequent. Life's style index was not related to CPO, Löe, ISHO and frequency of tooth brushing Pearson $\mathrm{p}>0.05$

Among the components of lifestyle there is significant difference in diet between male and female $U$ by Mann-Whitney $\mathrm{p}<0.05$

\section{Summary}

Objective: The objective of this research was to measure the lifestyle of the Elderly and relate it to the general and oral health status.

Material and Method: The sample consisted of 44 older adults, with 56.8\% female and $43.2 \%$ male. A clinical record has been used to record socio-demographic data, medical history and a questionnaire containing questions about food, physical activity and intellectual activity. In addition to containing items on general health, establishing scores equivalent to very healthy, healthy and unhealthy.

Results: There is no correlation between the lifestyle index associated with CPOD. The CPITN has been measured, there is no significant difference $p>0.05$ and the ISHO (oral hygiene). Systemic diseases, risk habits such as smoking and drinking alcohol have been reported.

Conclusion: There is no relationship between general and oral health with the lifestyle of the elderly. Pearson $\mathrm{p}>0.05$. With respect to lifestyle dimensions, there has been a significant difference in feeding scores between men and women, Mann-Whitney $\mathrm{Up}<0.05$ 


\section{Introduction}

Since 2007 there has been a change in the population pyramid in Peru, becoming according to the INEI, there are currently 2,700,000 older adults from a population of 30,135,875 people. These figures represent $8.9 \%$ of the total population. The growth rate is $3.3 \%$ and will be 3 million 727 thousand seniors in 2020 and 4 million 470 thousand in 2025 , with $12 \%$ of people 60 years of age and older [1] A. Adler said that the lifestyle and adaptation of the individual to reality form the basis of his psychic balance.

The World Health Organization considers lifestyle as the general way of life based on the interaction between living conditions and individual behavior patterns, which are determined by sociocultural factors and the personal characteristics of the individual [2]. In this way, he has proposed the following definition: "Lifestyles are patterns of behavior that have been chosen from the alternatives available to people, according to their ability to choose and their socioeconomic circumstances" The domains that integrate the lifestyle have included behaviors and preferences related to the type of food, physical activity, alcohol consumption, tobacco and other drugs, health responsibility, recreational activities, interpersonal relationships, sexual practices, work activities and consumption patterns [3]. The objective of the present study is to measure the lifestyle in the elderly and what is its result in the general and oral health status.

\section{Material and Method}

\section{Population and Sample}

A descriptive correlational, prospective cross-sectional, observational study was performed. The universe was made up of all older adults of "The House of the Elderly" from 60 years to older. The sample was 19 men and 25 women aged 60 to 78 years. They signed their informed consent [4].

A. Total edentulous patients with motor or mental disorders who cannot properly sanitize themselves have been excluded.

\section{Data Collection Technique}

A record was applied to record sociodemographic data.

A. Clinical history, a stomatological examination will be performed to evaluate: caries, periodontal disease, bacterial plaque. Were used: the CPOD Index to evaluate dental caries, the CPITN Index to assess periodontal status and the Greene and Vermillon OSHI Hygiene Index, to explore oral diseases, systemic diseases $[5,6]$.

B. A survey with questions, to know your lifestyle in the dimensions considered: food, physical activity, intellectual activity and knowledge and oral hygiene habits. The Cronbach Reliability Coefficient will be applied, as well as the correlations between the items and their domains. This first version of the instrument will be applied to a pilot group of 20 older adults to assess the level of understanding and reproducibility.

C. Respondents were grouped into 4 age groups:

i. $\quad 60-65$

ii. $\quad 66-71$

iii. $\quad 72-77$

iv. $\quad 78$ or more

\section{Statistic Analysis}

The statistical package SPSS will be used. Descriptive statistics will be performed. Chi-square test will be used to see association between lifestyle and each of the dimensions, and Spearman's $r$ to find a correlation between Oral Hygiene behavior with the health and function of the stomatognathic system [7].

\section{Results}

Examining the sample of the population of the elderly we have the highest percentage of the female sex with $56.8 \%$, the male $43.2 \%$ that make a total of 44 people, with an average age of 72.16 years and a DV of +6.59 grouped the patients in the study sample presented a healthy lifestyle 7 patients and unhealthy 37 . In general health, the most prevalent disease is major hypertension in men [11] and women [8], being the most affected age group of 72-77 years with $20.5 \%$ and followed by 78 or more with $13.6 \%$. Only three patients did not report any disease. Six patients had four systemic conditions. Stress was more prevalent in females with $20.5 \%$ and $6.8 \%$ in males and the most affected groups were 60 to 65 years and 72 to 77 years. With respect to periodontal disease, the excluded category reaches $37.12 \%$ due to the absence of index teeth. The prevalence of bleeding is $18.9 \%$ and calculations is $19.3 \%$ with $18.5 \%$ being healthy. Bags of 4 to $5 \mathrm{~mm}$ are presented in $5.3 \%$.

The CPO index is $19.98+6.45$, it allows to measure decay and its level is very high (WHO> 18) and analyzed CPO the carious ones have an average of 2.28, 14.80 of lost and an average of 5, 20 of shutters. The healthy teeth were 43 with an average of 40.40 . There is no correlation between CPO and lifestyle $[9,10]$.

The frequency of brushing presents a percentage of $43.2 \%$ with 2 max per day as well as health education 54\% if you were aware of the oral health talks, compared to $25 \%$ and $11 \%$ female vs. $9.1 \%$ and $11.4 \%$ male oral health. The diet based on the consumption of vegetables was higher with $27.3 \%, 31.8 \%, 20.5 \%, 18.2 \%$, $25.0 \%, 45.5 \%$ and $43.2 \%$ taking advantage of the female sex (very healthy). In physical activity it was very active in $29.5 \%$ of male sex and $15.9 \%$ of crafts in the female sex In intellectual activity he was very active in $40.9 \%$ of the female sex and writes $15.9 \%$ of the male. The Lifestyle index associated with CPOD, CPITIN, and ISHO there is no significant difference $\mathrm{p}>0.05$ (Tables 1-10). 
Table 1: Percentage distribution of the sample according to age and sex of the Elderly of the House of the Elderly of Squirting.

\begin{tabular}{|c|c|c|c|c|c|}
\hline \multirow{2}{*}{ Age } & \multicolumn{2}{|c|}{$\mathrm{F}$} & \multicolumn{2}{c|}{$\mathrm{M}$} & TOTAL \\
\cline { 2 - 6 } & $\mathrm{N}$ & $\%$ & $\mathrm{~N}$ & $\%$ & \\
\hline $60-65$ & 6 & $13.60 \%$ & 3 & $6.80 \%$ & $20.50 \%$ \\
\hline $66-71$ & 4 & $9.10 \%$ & 3 & $6.80 \%$ & $15.90 \%$ \\
\hline $72-77$ & 11 & $25.00 \%$ & 8 & $18.20 \%$ & $43.20 \%$ \\
\hline $78 \mathrm{a}+$ & 4 & $9.10 \%$ & 5 & $11.40 \%$ & $20.50 \%$ \\
\hline Total & 25 & $56.80 \%$ & 19 & $43.20 \%$ & $44.00 \%$ \\
\hline
\end{tabular}

Table 2: Lifestyle Index of the Population of the Elderly of the House of the Elderly of Squirting.

\begin{tabular}{|c|c|c|}
\hline Lifestyle & Frequency & $\mathrm{X}+\mathrm{DS}$ \\
\hline Poco Saludable & 37 & $46.59+4.29$ \\
\hline Saludable & 7 & \\
\hline Total & 44 & \\
\hline
\end{tabular}

Table 3: Diet or Food Habits such as the consumption of vegetables, fruits, sugar... according to the age and sex of the Elderly of the House of the Elderly of Squirting.

\begin{tabular}{|c|c|c|c|c|c|c|}
\hline Variables & \multicolumn{5}{|c|}{ Gender } \\
\hline & \multicolumn{3}{|c|}{ \% F } & \multicolumn{3}{c|}{ \% M } \\
\hline Feeding & $\mathbf{0}$ & $\mathbf{2}$ & $\mathbf{3}$ & $\mathbf{0}$ & $\mathbf{2}$ & $\mathbf{3}$ \\
\hline Vegetables & 2,3 & 27,3 & 27,3 & & 27,3 & 15,9 \\
\hline Fruits & & 25,0 & 31,8 & 23,0 & 25,0 & 15,9 \\
\hline Bread & 11,4 & 25,0 & 20,5 & 13,6 & 25,0 & 4,5 \\
\hline Sugar & 15,9 & 22,7 & 18,2 & 25,0 & 13,6 & 4,5 \\
\hline Between meals & 9,1 & 22,7 & 25,0 & 11,4 & 13,6 & 18,2 \\
\hline Out of home & 2,3 & 9,1 & 45,5 & 6,8 & 13,6 & 22,7 \\
\hline Ask for more & 2,3 & 11,9 & 43,2 & 4,5 & 13,6 & 25,0 \\
\hline
\end{tabular}

Table 4: Percentage distribution of Systemic Diseases of the Elderly of the House of the Elderly of Squirting.

\begin{tabular}{|c|c|c|c|c|c|}
\hline \multirow[t]{2}{*}{ Variables } & \multicolumn{5}{|c|}{ Sex } \\
\hline & $\mathbf{n}$ & Female & $\mathbf{n}$ & Male & Total \\
\hline Hypertension & 8 & $18,2 \%$ & 11 & $25 \%$ & $43,2 \%$ \\
\hline Diabetes & 7 & $15,9 \%$ & 1 & $2,3 \%$ & $18.20 \%$ \\
\hline Stress & 9 & $20,5 \%$ & 3 & $6,8 \%$ & $27.30 \%$ \\
\hline Osteo-articular & 10 & $22,7 \%$ & 6 & $13,6 \%$ & $36.40 \%$ \\
\hline Eyepiece & 13 & $29,5 \%$ & 15 & $34,1 \%$ & $63.60 \%$ \\
\hline Hearing aid & 3 & $6,8 \%$ & 9 & $20,5 \%$ & $27.30 \%$ \\
\hline
\end{tabular}

Table 5: Results of the CPO dental examination: Carious, absent and sealed component of the Elderly of the House of the Elderly of Squirting.

\begin{tabular}{|c|c|c|c|c|c|c|c|}
\hline & & & \multicolumn{2}{|c|}{ CARIADOS } & \multirow[t]{2}{*}{ LOST } & \multirow[b]{2}{*}{$\mathbf{n}$} & \multirow[t]{2}{*}{ OBTAINED } \\
\hline & $\mathrm{X}+\mathrm{DS}$ & $\mathbf{n}$ & & $\mathbf{n}$ & & & \\
\hline \multirow[t]{3}{*}{ CPOD } & 19,98 & 18 & $2.28 \pm 2,10$ & 44 & $14.80 \pm 8.13$ & 35 & $5.20 \pm 4.45$ \\
\hline & $\underline{x} 6.45$ & & & & & & \\
\hline & & $\mathrm{n}$ & & & & & \\
\hline Teeth & 10.40 & 43 & & & & & \\
\hline Healthy & $\pm 6,24$ & & & & & & \\
\hline
\end{tabular}

Table 6: Results of the CPITN periodontal examination: Sextant index teeth according to periodontal disease of the Elderly of the House of the Elderly of Squirting.

\begin{tabular}{|c|c|c|c|c|c|c|c|}
\hline \multirow[b]{2}{*}{ CODES } & \multicolumn{7}{|c|}{ TEETH INDEX } \\
\hline & $\begin{array}{c}\text { SEXT. SUP } \\
\text { OF THE }\end{array}$ & $\begin{array}{c}\text { SEXT. SUP } \\
\text { ANT }\end{array}$ & $\begin{array}{c}\text { SEXT HIS P } \\
\text { IZQ }\end{array}$ & $\begin{array}{c}\text { SEXT INF. } \\
\text { IZQ }\end{array}$ & $\begin{array}{c}\text { SEXT INF. } \\
\text { ANT }\end{array}$ & $\begin{array}{c}\text { SEXT. INF. } \\
\text { THERE }\end{array}$ & TOTAL \\
\hline \multirow[t]{2}{*}{ Healthy } & 7 & 16 & 7 & 6 & 11 & 2 & $18.50 \%$ \\
\hline & & & & & & & 49 \\
\hline \multirow[t]{2}{*}{ Bleeding } & 7 & 6 & 8 & 9 & 9 & 11 & $18.90 \%$ \\
\hline & & & & & & & 50 \\
\hline \multirow[t]{2}{*}{ Dental calculus } & 4 & 3 & 8 & 8 & 18 & 10 & $19.30 \%$ \\
\hline & & & & & & & 51 \\
\hline \multirow[t]{2}{*}{4 to $5 \mathrm{~mm}$ bag } & 4 & - & 2 & 2 & 1 & 5 & $5.30 \%$ \\
\hline & & & & & & & 14 \\
\hline \multirow[t]{2}{*}{ Bag larger than $6 \mathrm{~mm}$} & 2 & - & - & - & - & - & $1.51 \%$ \\
\hline & & & & & & & 2 \\
\hline \multirow[t]{2}{*}{ Excluded } & 20 & 19 & 19 & 19 & 5 & 16 & $37.12 \%$ \\
\hline & & & & & & & 98 \\
\hline
\end{tabular}


Table 7: Simplified Oral Hygiene Index (ISHO) of the Elderly of the House of the Elderly of Squirting.

\begin{tabular}{|c|c|c|c|c|}
\hline \multirow{2}{*}{ Unhealthy } & \multicolumn{2}{c|}{ Lifestyle } & \multirow{2}{*}{ Total } \\
\cline { 3 - 4 } Will & Good & $9,3 \%$ & $2,3 \%$ & $11,6 \%$ \\
\hline & Regular & $39,5 \%$ & $11,6 \%$ & $51,2 \%$ \\
\hline & Bad & $34,9 \%$ & $2,3 \%$ & $37,2 \%$ \\
\hline TOTAL & & $83,7 \%$ & $16,3 \%$ & $100,0 \%$ \\
\hline
\end{tabular}

Pearson's chi square $\mathrm{p}>0.05$
Table 8: Gingival Inflammation Index Löe Silness of the Elderly of the House of the Elderly of Squirting.

\begin{tabular}{|c|c|c|c|c|}
\hline \multirow{2}{*}{\multicolumn{2}{|c|}{ Unhealthy }} & \multicolumn{2}{c|}{ Lifestyle } & \multirow{2}{*}{ Total } \\
\cline { 3 - 4 } & Healthy & $2,3 \%$ & & $2,3 \%$ \\
\hline \multirow{2}{*}{ Löe-S } & Mild gingivitis & $2,3 \%$ & $2,3 \%$ & $4,7 \%$ \\
\hline & Moderate gingivitis & $62,8 \%$ & $11,6 \%$ & $74,4 \%$ \\
\hline & Severe gingivitis & $16,3 \%$ & $2,3 \%$ & 18,6 \\
\hline TOTAL & & $83,7 \%$ & $16,3 \%$ & $100,0 \%$ \\
\hline
\end{tabular}

Pearson's chi square $p>0.05$

Table 9: Means of dimensions: Food, Physical Activity, Intellectual activity and health according to age groups and sex of the Elderly of the House of the Elderly of Squirting.

\begin{tabular}{|c|c|c|c|c|c|c|c|}
\hline AGE & $\mathbf{n}$ & FEEDING $\mathrm{X}$ & $\mathbf{n}$ & PHYSICAL ACT X & $\mathbf{n}$ & ACT. INTELECTUAL X & n HEALTH $X$ \\
\hline $60-65$ & 9 & $15.11 \pm 2.89$ & & & 7 & $4.28 \pm 1.60$ & \\
\hline \multicolumn{8}{|l|}{$66-71$} \\
\hline $72-77$ & & & 19 & $3.21 \pm 1.84$ & & & \\
\hline 78 to + & 9 & $15.88 \pm 2.89$ & & & & & $22.44 \pm 1.66$ \\
\hline \multicolumn{8}{|l|}{ AGE } \\
\hline \multicolumn{8}{|l|}{ SEX } \\
\hline FEMALE & & $16.20 \pm 2.78$ & & $3.12 \pm 1.64$ & & & \\
\hline MALE & & & & & & $3.31 \pm 1.70$ & $21.68 \pm 3.30$ \\
\hline
\end{tabular}

Table 10: Total scores on food, physical activity, intellectual activity, health of the Elderly of the House of the Elderly of Chorrillos.

\begin{tabular}{|c|c|c|c|c|c|}
\hline & Total & Total & Total & Total & Total \\
Health & Academic & 200,000 & 197,500 \\
\hline U de Mann-Whitney & 115,500 & 228,000 & 209,000 & 525,000 & 387,500 \\
\hline W de Wilcoxon & 305,500 & 418,000 & 534,000 &,- 894 &,- 951 \\
\hline Z & $-2,911$ &,- 238 &,- 805 &, 371 &, 341 \\
\hline Mr. Asymptote (bilateral) & 0.004 & 0.812 &, 421 & 2 &, \\
\hline
\end{tabular}

Contrast statistics.

\section{Discussion}

The lifestyle index includes items that have already been validated and, given their importance, have been currently defined as "causal of diseases" [12-15]. The study population is of the Elderly. The lifestyle in medical literature is understood as synonymous with habits or form of human behavior [16-20]. No studies on lifestyle in relation to oral health have been found. Euribe studied lifestyle and the control of hypertension in hypertensive patients of the Senior Adult program. Euribe found an association between salt intake and control of hypertension [21]. Hypertension affects $24 \%$ of Peruvians of which 50\% corresponds to older adults. Thus, since GOHAI was an index designed and validated to measure oral quality of life in Geriatrics, it would be useful to measure lifestyle. This information could be used in educational, preventive and curative programs and also by other health professionals [18]. In the present case, this has been applied to 44 elderly patients, of which 7 are healthy and 37 unhealthy. Of the sample, $45.5 \%$ have done only primary, $52.3 \%$ are pensionable.

The female sex presented a healthy diet based on vegetables, vegetables and fruits, and applied the Mann Whitney U test $p<0.05$. Meneses Gómez provides the evidence that lifestyle changes affect the IQ scores. Among the variables that include a healthy lifestyle are physical activity, alcohol consumption, tobacco use, etc. The general health of older adults has been affected by up to 3 conditions, such as high blood pressure, diabetes and osteo-articular problems. In oral problems: dental caries measured with the CPOD index had an average value of 19.98 which corresponds to a high level (WHO) Bardales reports a CPO of 25.7 in 150 elderly patients. 
The missing dental component was the most frequent 14.80 Venezuela with 19.1 made with people over 60 [2]. In periodontal disease, dental stones predominated, then bleeding at probing. The healthy condition was $18.5 \%$, the predominant sextants predominated in $37.12 \%$ due to the loss of teeth. The 25.6 \& Older Adults 72-77 years have moderate gingivitis and $11.6 \%$ between 72-77, have severe gingivitis. The Lifestyle index associated with the ordered Simplified Oral Hygiene Index there is no significant difference, Pearson's chi square $\mathrm{p}>0.05$. There is no association between lifestyle and the Löe index, Pearson's chi square $p>0.05$.

Schooling and income do not influence lifestyle, Pearson's chi square $\mathrm{p}>0.05$.

\section{Conclusion}

1. The lifestyle of the Elderly Adults of the House of the Elderly of Chorrillos is
a) Healthy $15.9 \%$
b) Unhealthy $84.1 \%$

This means that the practice of habits does not strengthen a very healthy lifestyle.

2. The female sex has a healthy diet based on vegetables, fruits, 01 piece of bread, very little sugar, does not eat between meals, does not eat outside the home and does not request more.

3. The male sex has a higher percentage of very active physical activity, being surpassed in crafts by the female sex.

4. The female sex has very active intellectual activity.

5. General health is greatly affected by hypertension, diabetes, influence of stress. $27.3 \%$ of the sample has three systemic diseases. $13.6 \%$ have four.

6. The female sex observes better overall health than the male sex.

7. There is a very high $\mathrm{CPO}$, greater than that recommended by WHO at the age of 65 .

8. There is no relationship between lifestyle and CPO index.

a) $39.5 \%$ of females have moderate gingivitis

b) $14 \%$ of females have severe gingivitis

c) The female sex observed a higher frequency of tooth brushing with $25 \%$

9. There is no association between lifestyle and ISHO. Oral hygiene is $34.9 \%$ bad.

\section{Recommendations}

1. Need to create a program of promotion and prevention of oral health for the benefit of patients with 60 years or more. Send a message that reinforces attitudes.
2. Strengthen the help for self-care of the Elderly, defined as the set of actions and decisions taken by a person to maintain and improve their health, prevent, diagnose and mitigate the negative impact of the disease. (15)

3. Improve lifestyle and diet.

4. The health team considers the natural changes associated with aging.

5. Taking into account the biological and social functionality of aging, it is necessary to overcome the social and cultural barriers where the state, social organizations, the community, the family and each individual are involved.

\section{References}

1. Carriera SR, Carmona M, Quintana JZ, Alfaro X (2007) Oral Changes in the Elderly. Cuban Rev Stomatol 44(4).

2. renes W, Hoffmaister F (2004) Oral Health Situations in Older Adults: Problems and challenges. Costa Rican J Med Sci 25(3).

3. Pan American Health Organization. Regional Office of the World Health Organization. Oral health. Part II Diagnostic and Management Guide.

4. Govarnalusses BM (1999) Clinical Conference. Higher Institute of Medical Sciences. Faculty of Stomatology. Medisan 3(1): 53-56.

5. Gash A, Dolci FG, Campos-Castolo ME, Martínez-López J, RodríguezSuárez J (2009) Recommendations for Health Care for the Elderly. Conamed Magazine p: 45-59.

6. Candina RH, Batista HA (2009) The prevalence of Periodontopathies and some risk factors in the Elderly. Rev Cubana Invest Biomed 28(3): 73-82.

7. (2007) Ministry of Health. Clinical guide. Comprehensive Oral Health for Adults 60 years. Santiago: Minsal.

8. Nurguiendo SM, Velásquez RM, Mendoza DR, Pedraza Avilés GA (2011) Oral Health in elderly patients and their association with quality of life. Journal of Medical-Surgical Specialties 16(2): 110-115.

9. Coronado Gálvez JM, Díaz Vélez C, Apolaya Segura MA, Manrique González LM, Arequipa Benavides JP (2009) Perception of the quality of life related to the health of the Elderly resident in the city of Chiclayo. Min Med Per 26(4): 230-238.

10. Naples TN, García MM, Mariño GM, Sarabia MM (2006) Periodontal Disease in the Third Age. Medical Archive of Camaguey.

11. Goldbaum Moses. Lifestyles and modernity.

12. Mora, M, Villalobos D, Araya G, Ozols A (2004) Subjective perspective of the quality of life of the elderly, gender-related differences and the practice of recreational physical activity. MH Salud Magazine 1: 1-12.

13. Rangel Rivera JC, García del Prado LG, Castillo QM, Gutiérrez Hernández ME, Hernández GN (2009) Need to create promotion and prevention programs in the Elderly. Cuban Journal of Stomatology, 2009 and 46 (1): $1-9$

14. Ibañez Mancera NG, Libien PY, Díaz AN, Rodríguez PE (2011) Xerostomia (Hyposalivation) secondary to pharmacological treatment of arterial hypertension. ADM Magazine 68 (6): 283-289.

15. Antúnez NL, Sanjurio Álvarez CS, Heredia GE, Rodríguez RA (2006) Educational intervention on oral health in institutionalized rural people. Cuban Rev. Estomatol Vol. 4ํㅡ№ 4 . City of Havana.

16. (2011) From Assis Simões a.c., Carvalho D.M. to the reality of the oral buildup of the Southeast Brazil. Science \& Collective Saude, 16(6): 29752982.

17. Sánchez Ma , Elena V (2008) Evaluation of oral health status and its relationship with healthy lifestyles in the province of Salamanca. Doctoral thesis Salamanca. Spain. University of Salamanca. 
18. Meneses Gómez EJ (2010) Oral health and quality of oral life in the elderly. PhD thesis Complutense University of Madrid. Madrid.

19. Bardales Carreño LG (2003) Most prevalent oral clinical conditions and the need for oral rehabilitation in 150 elderly patients in the Ignacia R. Vda. from Canevaro. Lima 2003. Thesis to opt for the Title of Dental Surgeon. Inca Garcilaso de la Vega University. Lima-Peru.

\section{ISSN: 2574-1241}

DOI: 10.26717/BJSTR.2019.23.003849

Rosa Elizabeth Ysla Cheé. Biomed J Sci \& Tech Res

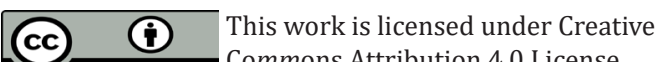

Submission Link: https://biomedres.us/submit-manuscript.php
20. Zavala GM, Vidal GD, Castro SM, Quiroga P, Klassen PG (2006) Social functioning of the elderly Science. Sick V 12 n 12 . Conception.

21. María del Rosario EJ (2010) Relationship between lifestyles and blood pressure control in hypertensive patients. Senior Adult Program at the René Toche Groppa Hospital. EsSalud - Chincha Alta, 2009. Thesis to qualify for the Degree in Nursing. San Martin de Porres University. Faculty of Obstetrics and Nursing. Lima-Peru.

$\begin{array}{ll}\text { BIOMEDICAL } & \text { Assets of Publishing with us } \\ \text { RESEARCHES } & \text { - Global archiving of articles } \\ & \text { - Immediate, unrestricted online access } \\ & \text { - Rigorous Peer Review Process } \\ & \text { - Anttps://biomedres.us/ }\end{array}$

